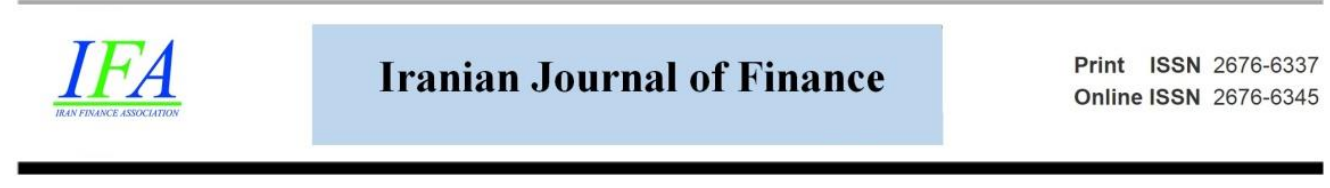

\title{
Offering Catastrophic Risk Management Framework by Alternative Risk Transfer Instruments to Islamic Capital Market with Cat Takaful (CT) Sukuk
}

\section{Hosaine Hasangholipoure}

PhD. Candidate, Department of Financial Engineering, Rasht Branch, Islamic Azad University, Rasht, Iran. (Email: h.yasouri@gmail.com)

\section{Ebrahim Chirani*}

*Corresponding Author, Department of Management, Rasht Branch, Islamic Azad University, Rasht, Iran. (Email: chirani@iaurasht.ac.ir)

\section{Seyed mozaffar Mirbargkar}

Department of Management, Rasht Branch, Islamic Azad University, Rasht, Iran. (Email: mirbargkar@iaurasht.ac.ir)

\section{Sina Kheradyar}

Department of Accounting, Rasht Branch, Islamic Azad University, Rasht, Iran. (Email: kheradyar@iaurasht.ac.ir)

Document Type: Original Article

Received: 2020/09/09
2021, Vol. 5, No. 3. 78-107.

Published: 2021/10/05

\begin{abstract}
Out of 64 possible catastrophic events in the whole world, about 34 of them have been experienced in Iran; more than $80 \%$ of the regions are exposed to natural disasters risks such as earthquakes exposure. Domestic insurance capacity does not cover this volume of risk and the need for external reinsurance capacity is always felt. Catastrophe bonds structure as a financial $\&$ insurance innovative solution (Alternative Risk Transfer Instruments) allows an issuing institution to transfer catastrophic exposures and risk to capital market's investors by creating capital relief and additional risk capacity for our insurance industry. We adjusted the formal cat bonds structure with the Islamic
\end{abstract}


jurisprudence. According to the systematic review research method 8 steps, the Sukuk model was implemented based on the extracted concepts from 23 Farsi articles and 50 English articles. After that interviews by 18 experts who were selected by purposive \& Snowball sampling, The Delphi method was used to obtain the opinion of experts and their opinion was modified and implemented in the final model. In the open coding stage, 415 concepts were extracted which were classified into 10 categories and finally presented in 4 Propositions/themes. The trustworthiness and authenticity did base on the fourstage model of Lincoln and Guba and also its complementary step. We finally suggested that the catastrophe bond instrument could be issued in the form of a cat takaful (CT) sukuk contract template, as a solution for transferring catastrophic risks to the Islamic financial market.

Keywords: Takaful; Insurance Risk Securitization; Catastrophe Bond; Insurance Sukuk; Catastrophe Risk

DOI: 10.30699/IJF.2021.247524.1156

Publisher: Iran Finance Association Copyright: author(s)

Type of License: Creative Commons License (CC-BY 4.0)

\section{Introduction}

Iran with more than 120,000 casualties with a lot of asset losses is among of the top 10 countries in the world in terms of natural hazards exposure, and with only one percent of the world's population, it has been allocated with $6 \%$ of the world's natural disaster fatality. Based on a research and report (Iranian Studies Group at MIT, 2004), Out of the total cities of Iran, only 33\% are in low-risk areas and about $75 \%$ of the country's population centers are at floods risk and more than $80 \%$ of the countries are exposed to other natural disasters risks such as earthquakes exposure. To better understand the issue, it is enough to know that only in the case of the devastating flood of " March 21 2019", which affected 4 provinces of the country and left 4 dead, 4 thousand billion tomans of the direct economic damage was caused. Iran is one of the major seismic countries in the world. (NDMO, 2017). out of 64 possible catastrophic events in the whole world, about 34 of them have been experienced and occurred locally, including: earthquakes, floods, storms, water and environment pollution, tsunami, pests and plant diseases, land fluctuations, droughts, etc. (EM-DAT. 2021). (ADRC. 2021). (UNDRR. 2021), Meanwhile, up to 250 natural disasters occur in Iran and 1.5 million Iranians are affected by natural disasters every year. During human life in different societies, natural and catastrophic events lead to life-threatening destructions, and financial losses continue to be incurred. In other words, the risk of an accident or disaster is 
more a direct result of human activities. Societies use scientific and technological capabilities by using financial innovative methods and capital market potentials to be able to cope with these disasters and transfer the catastrophic risks to reduce the amount of damage caused by such perils. Catastrophe bonds structure allows an issuing institution to transfer catastrophic exposures and risks to investors by creating capital relief and additional risk capacity. The issue of this research is that what is the practical pattern of issuing catastrophe bonds in relation to the financial and insurance system of Islamic finance? And given that the securities in the country are issuing in the form of a Sukuk, what is the practical model of this Sukuk which can be issued in Islamic financial markets?

\section{Research Background}

Both hurricane Andrew in 1992 and the Northridge earthquake in 1994 caused insured losses of more than $\$ 12$ billion. While the magnitude of these losses was unprecedented, the losses were small compared to the potential losses that could result if a major storm or earthquake would hit a more developed area. For example, modelers estimate that insured losses would exceed $\$ 75$ billion if a hurricane like Andrew were to hit Miami, Florida. Similar estimates exist for an earthquake in San Francisco. (Note that these estimates are for insured losses. Uninsured losses also would be substantial, especially for earthquakes.) To the extent that catastrophe risk is shared, it usually occurs in two steps. First, individuals and businesses purchase insurance coverage from primary insurers. Second, primary insurers purchase reinsurance from reinsurers that typically operate worldwide. In this way, catastrophe risk is shared around the globe. The potential losses from catastrophes have led financial researchers to address the question about market solutions that could lead to a more efficient allocation of catastrophe risk. (Niehaus, 2002)

Insurance risk lacks a clear, unambiguous definition. It is generally defined as the risk being taken on by insurance companies in selling insurance protection. This could be interpreted in a very broad sense to include all risks faced by an insurance company during its operations. So, it could be said that investing in insurance risk is the same as investing in an insurance company. Considered in this broad sense, insurance risk includes all traditional investment risks market, credit, operational and others, as well as the insurance risk, defined more narrowly - that of insurance claims (obligations under insurance policies) being greater than expected, or greater than a certain level that the insurance company wants or is permitted to take. Even this definition is imprecise since all the risks are intermingled and cannot be fully decomposed into individual elements. The more narrowly defined type of insurance risk 
would apply in cases of higher-than-anticipated losses due to factors such as random statistical fluctuations in the number of insurance claims or their severity, natural catastrophes or man-made disasters, spikes in mortality or fundamental shifts in longevity, and many others. Often such types of insurance risk either cannot be transferred to investors purely through the traditional equity or debt instruments issued by insurance companies or are best transferred to capital markets differently. Based on the Alternative Risk Transfer (ART) concept, Insurance-linked securities (ILS) are structured to transfer to investors this type of risk and are specifically designed to address unique issues of insurance companies. Most have to do with the transfer of "pure" insurance risk where other risks are excluded or minimized. They afford investors exposure to risks that are different from those embedded in traditional securities, and that is often only weakly uncorrelated to the behavior of the financial markets. (Krutov, 2010, p 4), For a better understanding of the literature, the subject is presented in two global \& Islamic financial instruments separate sections

\section{A. Global experience}

\section{- Alternative Risk Transfer (ART)}

The ART market is the combined risk management marketplace for innovative insurance and capital market solutions, while ART is a product, channel or solution that transfers risk exposures between the insurance and capital markets to achieve stated risk management goals. In its broadest sense ART can be viewed as an all-encompassing sector that involves multiple asset classes and risks, conduits, products, terms, industries, and legal vehicles. To create an optimal ART-based risk management plan, multiple products, vehicles, and solutions are often used in combination. (Banks, 2004, p49). Derivatives can be used to neutralize the downside effects of a single risk, diversify a portfolio of exposures (and, in so doing, reduce risk), and provide capacity to engage in additional risky business. Any of these can be accomplished when a company identifies the exposure it intends to protect or the portfolio it wants to diversify and arranges a transaction that provides a compensatory payment when (if) the underlying exposure generates a loss. Since derivatives are not indemnity contracts, a company generally accepts some amount of basis risk. While certain financial risks can be matched quite precisely via derivatives (e.g., specific exposure to exchange rates or interest rates), insurance-related risks often cannot (e.g., specific exposure to catastrophe or weather). The tradeoff in accepting more basic risk is a reduction in the specter of moral hazard and the creation of a cheaper risk management tool. Derivatives have certain benefits and characteristics that can make them an important part of an ART solution. (Banks, 2004, p 149-150) 
- Insurance-linked securities

ILS structures have been refined and customized in recent years. The basic architecture has remained relatively unchanged: an insurance or reinsurance company issues securities through an SPE and bases repayment of interest and/or principal on losses arising from defined insurance events. If losses exceed a predetermined threshold, the insurer/reinsurer is no longer required to pay investors any interest; if structured with a non-principal protected tranche all, or a portion of the principal can also be deferred or eliminated. Through this elemental structure, a new risk supply is created: the issuer passes a defined exposure to capital markets investors, lowering its risk profile; this provides capital and reserve relief and allows new business to be written. Importantly, the mechanism bridges the insurance and capital markets, permitting the insurance sector to tap into the tremendous supply of capital held by investors. Most ILS issuance has occurred in the catastrophic risk sector, through securitization of earthquake, hurricane, and windstorm risks; these are collectively known as catastrophe (cat) bonds. The standard cat bond structure is quite similar to other securitized capital markets' structures, except that a special-purpose reinsurer (SPR), rather than an SPE trust, act as the issuance vehicle; we consider this point below. Notes are issued to investors and the trustee invests proceeds to generate a return (which might be fixed by a swap); the return is supplemented by payment of premium from the ceding company. The collateral in the trust account is used to repay the principal at maturity unless a catastrophic event triggers a reduced payout; if this occurs, investors may not receive interest and/or principal on a timely basis, if at all (in some cases they will only receive recompense after all claims and contingent liabilities, arising from the insurable event have been paid). By reducing or eliminating the payout to investors in the event a defined catastrophic event strikes, the ceding company mitigates its exposure to that event. (Banks, 2004, p 117-119). To clarify the discussion, the following chart, show how risks are transferred in insurance and reinsurance.

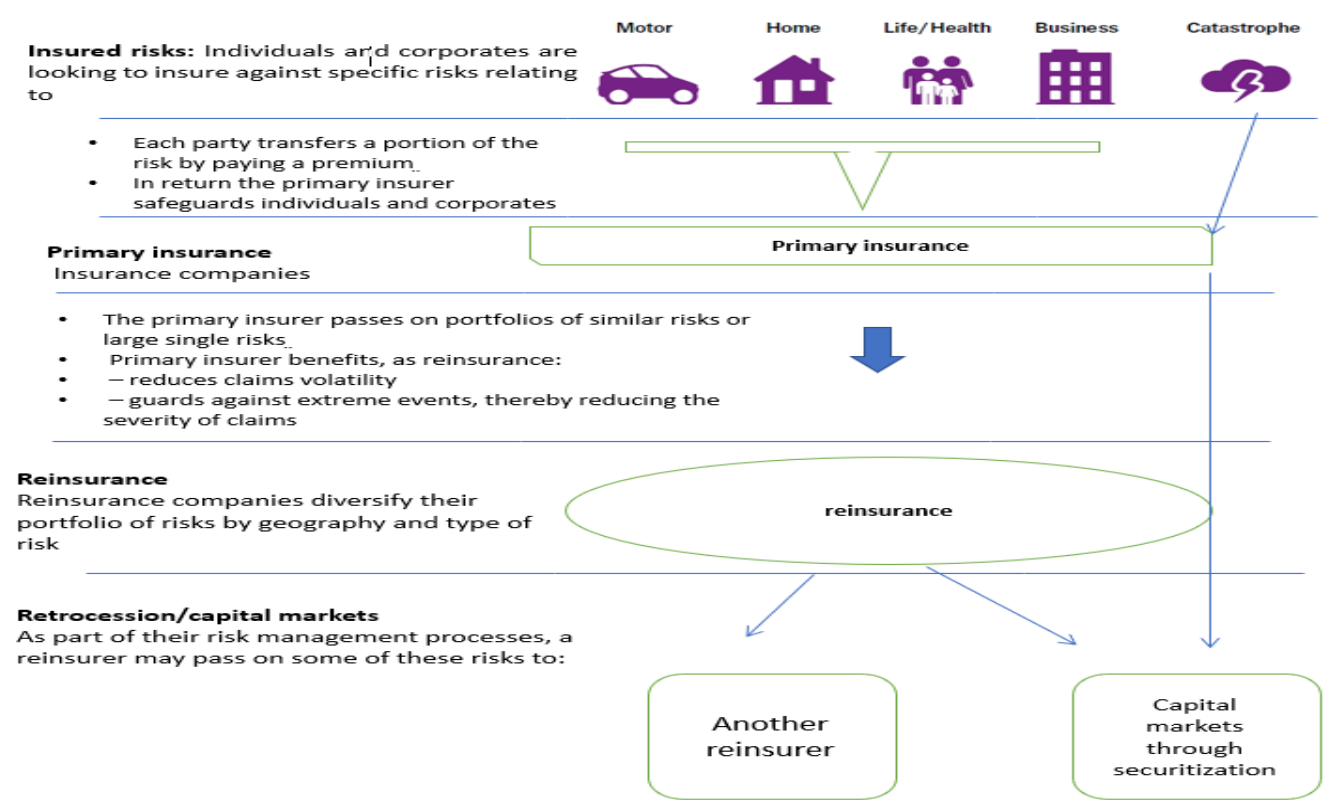

Figure 1- How risks are transferred in insurance and reinsurance 
- Catastrophe bonds

Several capital market instruments have been developed in the past decade to enhance insurers' ability to manage catastrophe risk. (One innovation has been catastrophe contingent equity and debt securities whereby insurers prearrange to issue equity or debt if a catastrophe occurs.) The more commonly used capital market innovation, however, has been catastrophe bonds. With these securities, investors agree to forgive some of the principal and/or interest payments on a debt instrument if a specified catastrophe occurs. If a catastrophe does not occur, then investors receive their principal plus a coupon that typically is well above LIBOR. (Niehaus, 2002)

- Standard structures

The standard catastrophe bond is like the other securitized capital markets structures.

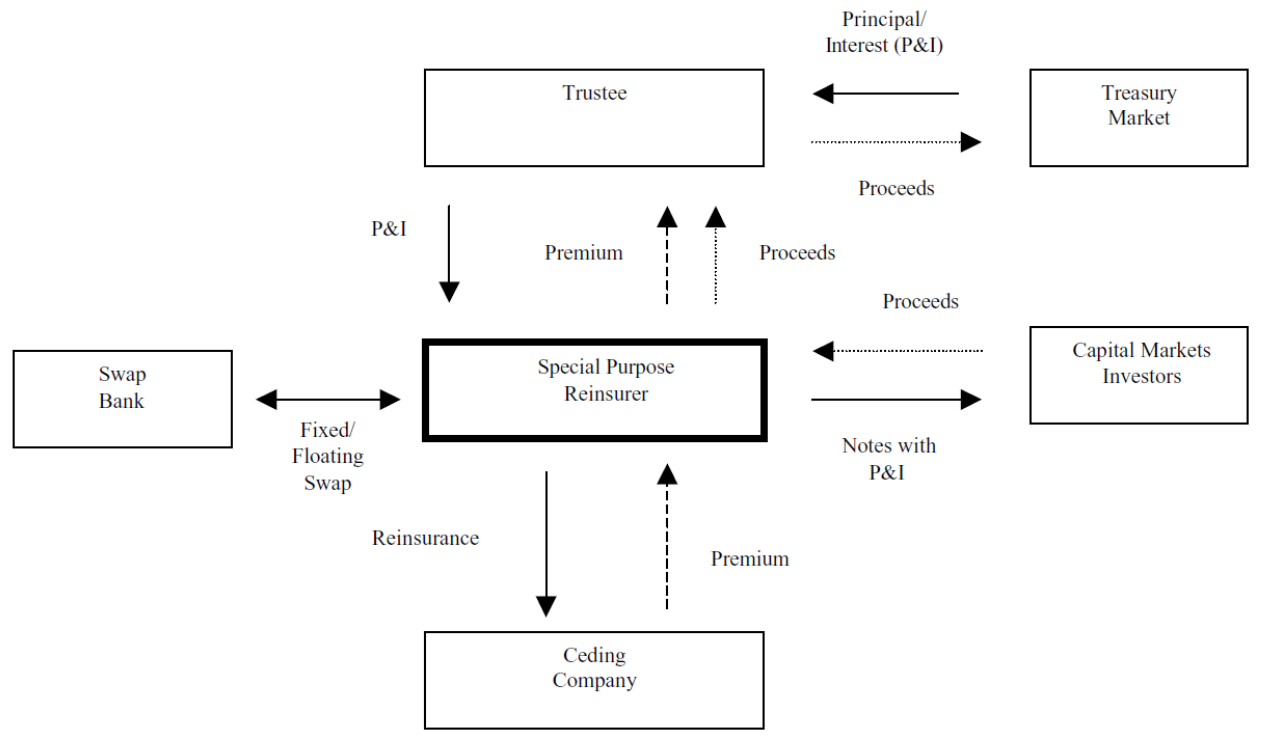

Figure 2-The standard catastrophe bond structures

A special-purpose entity (SPE) trust or a special purpose reinsurer (SPR) acts as an issuance vehicle, selling notes to investors, passing proceeds to the trustee for further reinvestment, and providing an indemnity contract to the issuing company. The return is generated through reinvestment and the premium payment of the issuing company from the investor coupon that becomes due and payable periodically; the invested proceeds held in the trust account are used to repay the principal at maturity. If a named catastrophic 
event occurs, the trustee withholds interest and/or principal payments temporarily or permanently. Since the issuing company will be exposed to losses on its underlying catastrophe risk but will no longer need to provide payments to investors, it has effectively used the capital markets investor base to hedge its risk.

- Triggers

Catastrophe bonds can be structured with indemnity, parametric, or index triggers that reference single or multiple events; each version has its own characteristics, advantages, and disadvantages. Regardless of the trigger type, most bonds are structured with initial deductibles (e.g., first loss retention by the issuer) and caps (e.g., maximum 'payout' or protection by investors to the issuer).

a. Indemnity triggers

These types of triggers are based on an issuer's actual exposure to a particular catastrophe (or series of catastrophes); investors absorb any losses that occur as a result of a specified event by relinquishing principal/interest (after taking initial retentions and a maximum event loss cap into account). As a result of this 'perfect match', the issuer eliminates any instance of basis risk. Naturally, a precise contract of coverage gives rise to moral hazard risk (i.e., the issuer, knowing that coverage is available through the securitization mechanism, will be less diligent in its underwriting standards or corporate behavior).

b. Parametric triggers

These types of triggers are based on one or more physical parameters associated with a peril, such as location and intensity (e.g., for an earthquake this can be the location of the epicenter and the magnitude of the event, for a hurricane, it may be the location of landfall and the minimum central pressure or average sustained wind speed). Parametric structures focus primarily on the event location and intensity rather than structural vulnerabilities (the vulnerabilities must still be evaluated, but only as a secondary step). If an event that meets the criteria defined by the parametric trigger occurs and generates losses, principal and/or interest payments are suspended. Since the match between an issuer's exposure and the parametric characteristics is not perfect, basis risk exists; however, moral hazard decreases and analytics need not be calibrated to the issuer's specific portfolio.

c. Index triggers

These types of triggers are based on a recognized industry loss index. In 
practice, industry losses can be derived from granular property databases (e.g., to the level of a zip code/postal code, which, depending on locale, corresponds to approximately 2000 household's/business operations), including the number of risks, value by type, occupancy, coverage, and business.

- Pricing

Pricing of catastrophe bonds is the focus of much attention given the complex and illiquid nature of the securities. From a theoretical perspective, catastrophe bonds should be priced at a level that approximates catastrophe reinsurance prices, with an allowance for friction costs. (Banks, 2005)

\section{B. Islamic financial instrument}

- Sukuk

The word Sukuk is plural for a certificate (Sakk) of ownership of a given class of assets that a borrower gives to a lender as proof of ownership. Therefore, Sukuk securities are debt instruments that require the creation of assets in a separate entity, these assets being owned proportionally by the lenders, the fund providers. Full asset-backed lending is a fundamental principle of Sukuk contracting. In the picture below, we provide a comparison of the fundamental principles underlying the contract specifications of Sukuk funding to conventional debt funding contracts. (ARIFF, 2014)

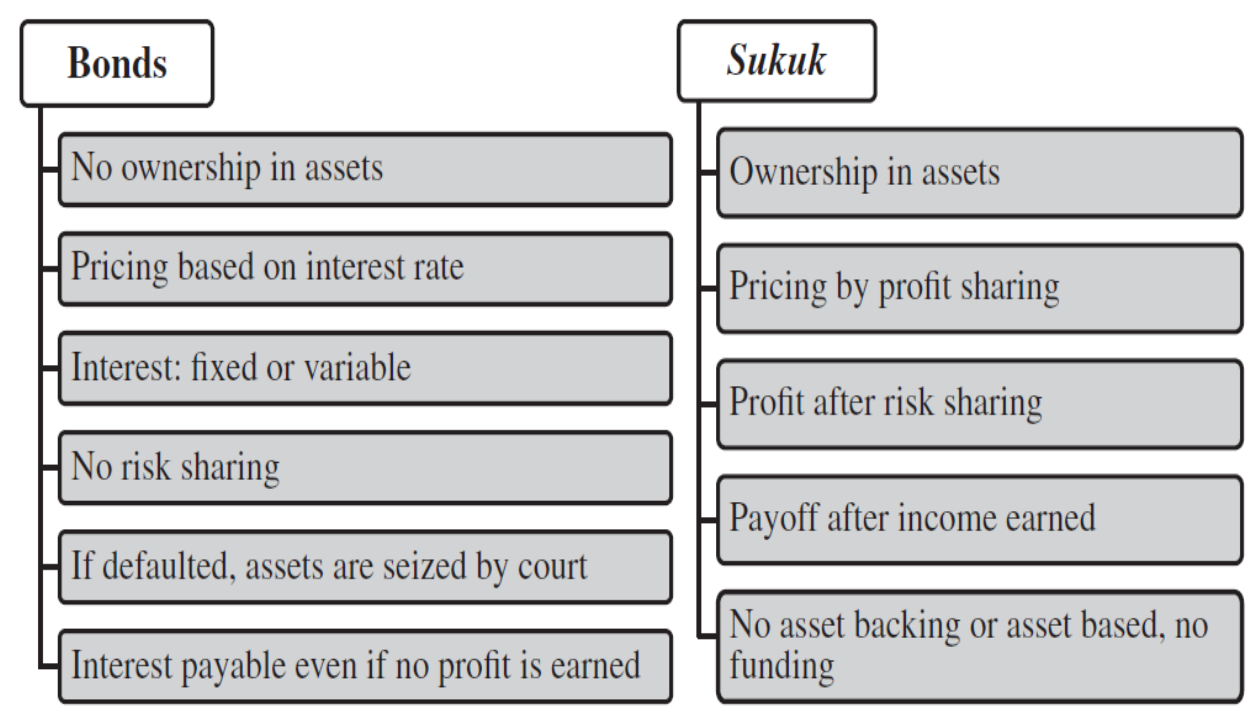

Figure 3- Fundamental Principles of Sukuk Security Compared to Conventional Debt Security. (ARIFF, 2014, p18) 


\section{- Classification Sukuk type}

Classification for Sukuk is based on their financial characteristics, such as pure debt, equity-based, asset-backed, or discount instruments. Each of the main categories may then, if necessary, be subcategorized to accommodate various types of contracts. To accommodate various types of asset-backed Sukuk contracts, and based on their intrinsic purpose, three more subcategories have been created: property-backed (semi collateralized) Sukuk, advance or deferred payment Sukuk, and project financing Sukuk. These classifications are summarized in the picture below.

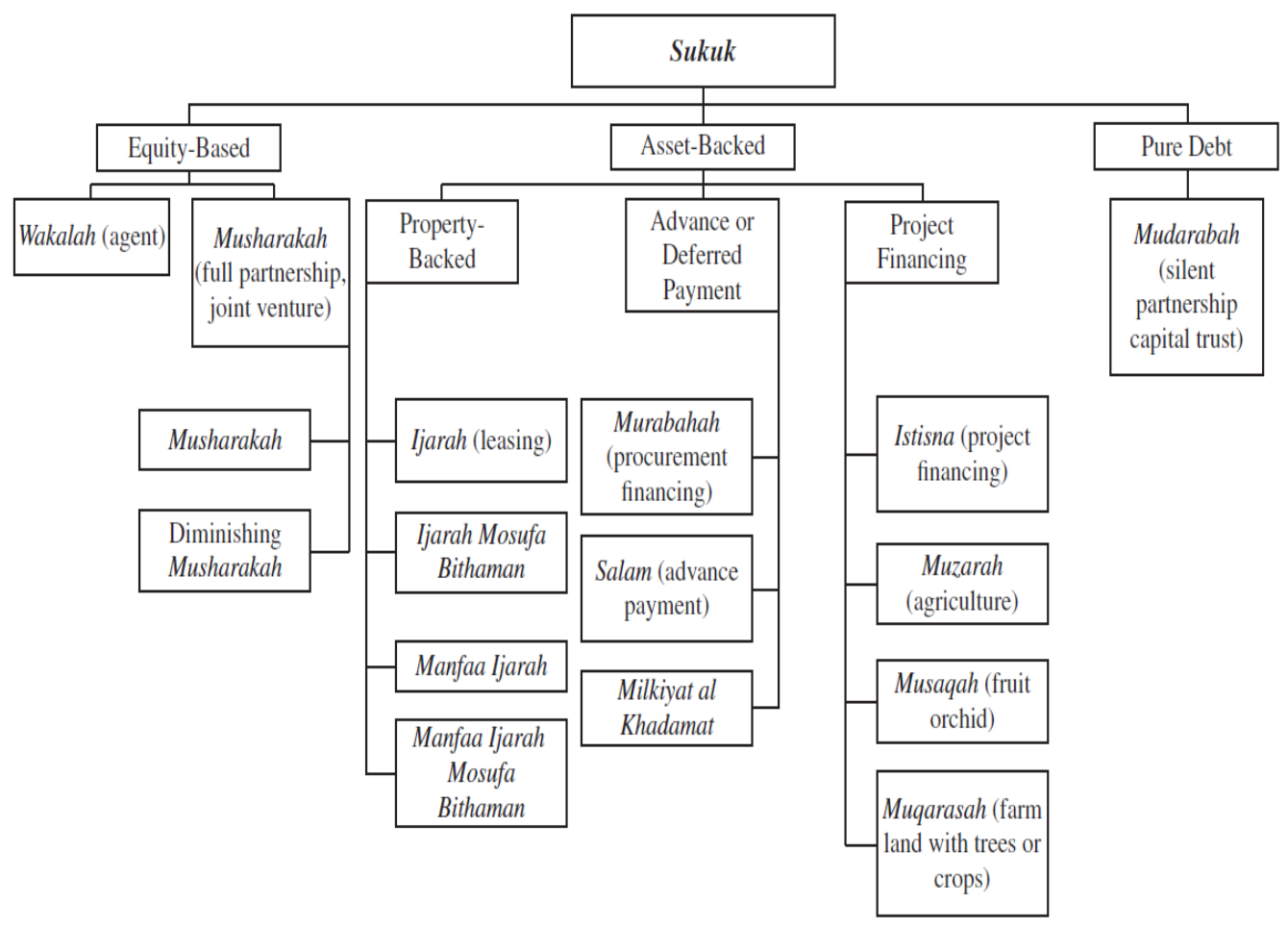

Figure 4-Classification of Sukuk Contracts Based on Their Financial Characteristics. (ARIFF, 2014, p 27)

11 types of Sukuk have been checked and studied in Iran. Each of these Sukuks are used for a specific contract and a certain function. During the surveys and based on the consultation and interview with the head of Iran sharia board of Securities and Exchange Organization. To provide the possibility of issuance of insurance Sukuk, Al-Wakala's contract was recognized as the best type of contract. The summary information is presented below. 
Table 1. Jurisprudence Categorization of Islamic Securities (Sukuk) (RDIS, 2017)

\begin{tabular}{|c|c|c|c|c|c|c|c|c|c|}
\hline 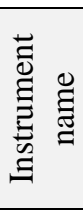 & 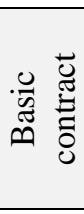 & 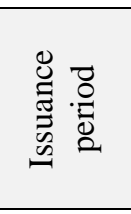 & 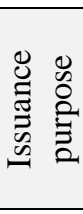 & 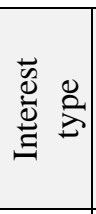 & 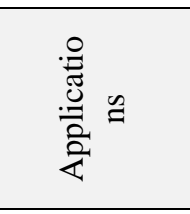 & 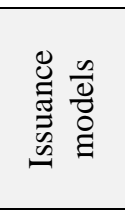 & $\begin{array}{l}\text { The nature } \\
\text { of } \\
\text { secondary } \\
\text { market } \\
\text { transactions }\end{array}$ & 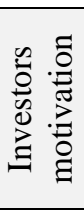 & 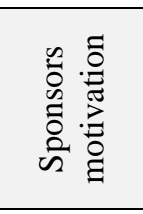 \\
\hline \multirow[b]{2}{*}{$\begin{array}{l}\frac{\pi}{\pi} \\
\frac{\pi}{\pi} \\
3\end{array}$} & \multirow[b]{2}{*}{$\begin{array}{l}\frac{\pi}{\pi} \\
\frac{\sqrt{\pi}}{\pi} \\
\frac{\pi}{\pi} \\
\frac{1}{4}\end{array}$} & \multirow[b]{2}{*}{ 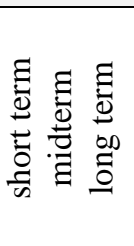 } & \multirow[b]{2}{*}{ 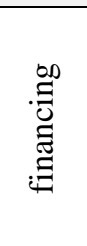 } & \multirow[b]{2}{*}{ 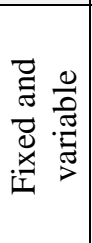 } & \multirow[b]{2}{*}{$\begin{array}{c}\text { Insurance } \\
\text { Sukuk } \\
\text { (Mousavian, } \\
\text { 2007) }\end{array}$} & Special & \multirow[b]{2}{*}{$\begin{array}{l}\text { Based on } \\
\text { the Jointly } \\
\text { sale and } \\
\text { purchase of } \\
\text { assets and } \\
\text { services }\end{array}$} & \multirow[b]{2}{*}{ 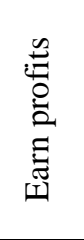 } & \multirow[b]{2}{*}{$\begin{array}{l}\text { Investing } \\
\text { in } \\
\text { economic } \\
\text { activity }\end{array}$} \\
\hline & & & & & & 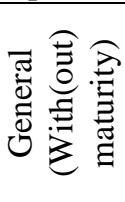 & & & \\
\hline
\end{tabular}

Islam confirms and signs every rationalized contract, which does not have a specific or general prohibition (Mousavian, 2009, p 78); so all financial and trading instruments can be used if they are in accordance with the Islamic trading rules. And the five principles of Islamic trading rules are as follows:

\section{The principle of prohibition of the Akal Mal Bel Batel}

The financial instrument cannot be designed and defined so that someone's money and property are transferred to the other side unduly.

\section{The principle of prohibition of the Zarar \& Zerar}

The instrument to be designed should not be detrimental, nor to the parties involved in the contract and neither to the community.

\section{The principle of prohibition of the Gharar}

The instrument to be designed should not be ambiguous, it must be completely transparent. In this sense, the parties to the contract know what their rights and responsibilities are, If the pillars of the contract are vague and imprecise, from the Islamic point of view, the bargain is Gharary and void.

\section{The principle of prohibition of the Riba}

Riba is among the great sins, and there should not be any financial instrument and contract resulting in Riba.

\section{The principle of prohibition of the Maysir}

According to the Quran's explicit verses, gambling is a devilish and evil practice and should be avoided and the designed instrument should not have a gambling form. (Mousavian, 2009, p 77-187) 
- Takaful

Takaful is an Islamic insurance concept that is grounded in Islamic muamalat (banking transactions \}, observing the rules and regulations of Islamic law. Takaful is basically a system of Islamic insurance based on the principle of Ta'awun (mutual assistance) and Tabarru (voluntary contribution\}, where the risk is shared collectively by the group. It is operated on the basis of shared responsibility, brotherhood, solidarity and mutual cooperation or assistance, which provides for mutual financial security and assistance to safeguard participants against a defined risk. The word Takaful is derived from the Arabic verb Kafala, which means to guarantee; to help; to take care of one's needs. This concept has been practiced in various forms for over 1400 years. Muslim jurists acknowledge that the basis of shared responsibility in the system of Aquila as practiced between Muslims of Mecca and Medina laid the foundation of mutual insurance. It is based on the concept of social solidarity, cooperation, and mutual indemnification of losses of members. It is a pact among a group of persons who agree to jointly indemnify the loss or damage that may inflict upon any of them, out of the fund they donate collectively. (SECP .2019) In fact, Takaful is a mutual guarantee or security provided by a group of people living in the same society, against a defined risk or catastrophe befalling on one's life, property or any form of valuable thing (Billah, M. M. 2001). Based on the research and studies conducted by the researcher from various sources, the structure of Takaful is summarized as follows:

Conventional insurance suffers from the following three impermissible factors:

- Interest

- Qimaar (Gambling)

- Gharar (Excessive Uncertainty)

A conventional insurance contract is a commutative contract (compensatory and bilateral), in which premium is the cost and the sum insured/assured/covered is the subject matter. There will always be fluctuation in the money involved and being a sales contract with money being exchanged from both sides, any such fluctuation will automatically fit the description of "interest". interest is, staying relevant to a financial institution, defined as one party given money in exchange for less or more money, which is exactly what happens in a conventional insurance company that receives premiums and pays less or more money in return, depending on whether the covered risk materializes. Likewise, gambling also is a fundamental part of the conventional insurance contract. Gambling is defined as a transaction whereby any of the contracting parties, after placing their goods or money at stake, can win or lose the other stake depending on an uncertain outcome without compensation. 
Hence, one party wins the other amount completely without paying anything in return or loses everything without being paid anything in return. Finally, the third damning featured of a conventional insurance contract is "Gharar", translated as "uncertainty". In a technical sense, it means "at least one party's compensation is being subject to uncertainty due to an uncertainty in the very object being contracted". In insurance, the insured does not know for sure whether he will be paid his capital with interest, or will be paid the insured sum in case the risk for which he insured materializes, and might end up receiving more than he paid to the insurer. This excessive uncertainty, when coupled with the price he pays, the subject matters for which he pays for the time period over which his payments are distributed, render the conventional insurance contract impermissible in Islamic Shariah. (Takaful-an introduction- Pak-Qatar General Takaful-2019).

Table 2. The Deference Between Takaful and Conventional Insurance

\begin{tabular}{|l|l|l|}
\hline \multicolumn{1}{|c|}{ Section } & \multicolumn{1}{|c|}{ Takaful } & \multicolumn{1}{c|}{ Conventional Insurance } \\
\hline Nature of Contract & $\begin{array}{l}\text { Takaful is a Tabarru' based } \\
\text { contract } \\
\text { Hybrid structure with a } \\
\text { combination of donation and } \\
\text { agency or profit-sharing } \\
\text { contracts. }\end{array}$ & $\begin{array}{l}\text { Exchange contract: buying and } \\
\text { selling } \\
\text { a contract whereby policies are } \\
\text { sold and the policyholders are } \\
\text { the purchasers. }\end{array}$ \\
\hline Strategy & Sharing of Risk & Transferring of Risk \\
\hline Contribution/ & $\begin{array}{l}\text { are owned by takaful fund(s). } \\
\text { The contribution can be in the } \\
\text { form of full or partial } \\
\text { donations to takaful fund(s). }\end{array}$ & $\begin{array}{l}\text { Whereas the premiums paid by } \\
\text { the } \\
\text { insured belongs to the insurance } \\
\text { company }\end{array}$ \\
\hline Investment & Shariah-compliant investment & Equity/debt-no restrictions \\
\hline Company & $\begin{array}{l}\text { As the shareholders act as } \\
\text { agents on behalf of } \\
\text { participants, } \\
\text { the company is called the } \\
\text { "operator" instead of the } \\
\text { "insurer." }\end{array}$ & $\begin{array}{l}\text { Relationship between } \\
\text { policyholders } \\
\text { and the company is on a one-to- } \\
\text { one } \\
\text { basis. }\end{array}$ \\
\hline Re -Takaful & $\begin{array}{l}\text { The takaful fund is owned by } \\
\text { participants, who bear the } \\
\text { underwriting risk. }\end{array}$ & $\begin{array}{l}\text { The shareholders bear the } \\
\text { underwriting } \\
\text { risks. }\end{array}$ \\
\hline Underwriting Loss & $\begin{array}{l}\text { No provision for underwriting } \\
\text { profit } \\
\text { The operator is not the owner }\end{array}$ & $\begin{array}{l}\text { Insurance companies will make } \\
\text { a profit } \\
\text { if the claims are lesser than the } \\
\text { premium }\end{array}$ \\
compang
\end{tabular}


Iranian Journal of Finance, 2021, Vol. 5, No. 3 (Hasangholipoure,H.)

\begin{tabular}{|c|c|c|}
\hline Section & Takaful & Conventional Insurance \\
\hline Surplus & $\begin{array}{l}\text { of } \\
\text { this amount }\end{array}$ & \\
\hline Section & Takaful & Conventional Insurance \\
\hline Underwriting Policy & $\begin{array}{l}\text { Underwriting techniques + } \\
\text { Shariah framework of Halal } \\
\text { and Haram }\end{array}$ & Only Underwriting techniques \\
\hline Claims & $\begin{array}{l}\text { Payable from Participant's } \\
\text { Takaful Fund ( Waqf Fund) }\end{array}$ & $\begin{array}{l}\text { Payable from the overall fund of } \\
\text { the } \\
\text { company }\end{array}$ \\
\hline Surplus & $\begin{array}{l}\text { Could be given to the } \\
\text { Participants }\end{array}$ & $\begin{array}{l}\text { owned by the insurer and } \\
\text { Belongs to Company } \\
\text { Shareholders }\end{array}$ \\
\hline Deficit & $\begin{array}{l}\text { Qardh-al-Hasan is given to the } \\
\text { Participants Takaful Fund }\end{array}$ & $\begin{array}{l}\text { Financed from shareholder's } \\
\text { fund i.e. } \\
\text { company }\end{array}$ \\
\hline Salvage/ Recoveries & Belongs to Waqf Fund & $\begin{array}{l}\text { Belongs to the Insurance } \\
\text { Company }\end{array}$ \\
\hline
\end{tabular}

According to studies, there are 4 types of Takaful contracts as follows:

a. Wakalah Model

This model, the wakalah (agency) contract, is used for both underwriting and investment activities of takaful fund(s). Although the wakalah contract has been practiced widely by many takaful operating companies in underwriting activities, it is rarely adopted for investment activities. With regard to the underwriting activities, the takaful operator acts as a wakeel (agent) on behalf of participants to manage the takaful fund(s) whereby the operator receives contributions, pays claims, and arranges re takaful and all other necessary actions related to takaful business. In exchange for these tasks, the company charges each participant a predefined fee known as a wakalah fee. This fee is front-loaded and calculated as a percentage of the contribution paid by the participant. the wakalah fee is deducted initially and goes directly to the shareholders' fund as an income for the operator. The remaining contributions after deducting the wakalah fee are credited to the participants' funds. The operator manages the takaful fund(s) and pays all the direct expenses incurred by the participants such as re-takaful arrangement cost, legal costs to settle claims, and claims incurred from the takaful fund(s). 


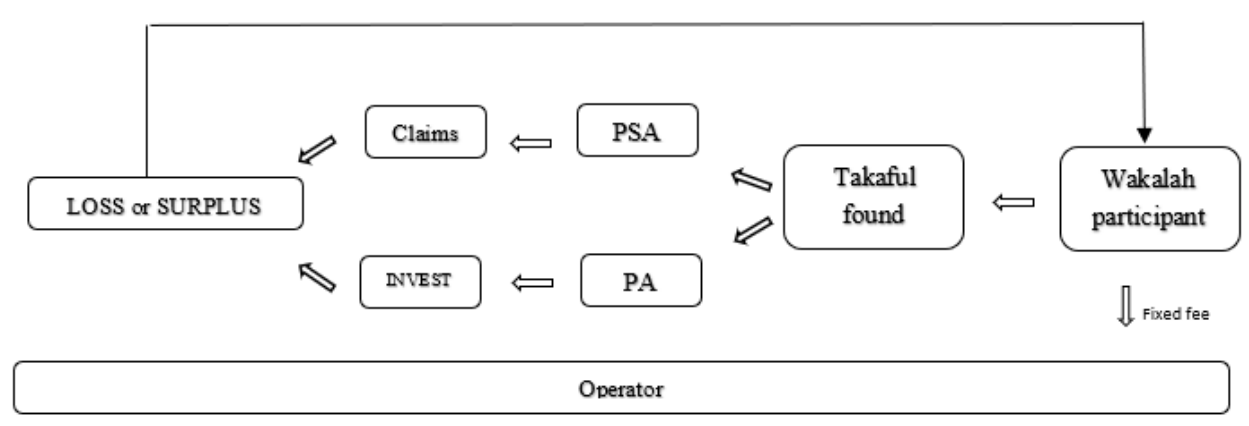

Figure 5. Takaful Wakalah Model

b. Mudarabah Model

Under this model, the operator acts as mudarib on behalf of participants who provide the funds in the form of contributions called rab al-mal. The operator and the participants should agree on the profit-sharing rate at the commencement of the takaful contract. This model is unique in that there is only one contract, the mudarabah contract, to cover both underwriting and investment activities. the contributions paid by the participants are credited to the takaful fund without any deduction. Then, all the direct expenses such as retakaful, claims payment, and other direct expenses are charged to the takaful fund(s) while the indirect expenses such as salaries and rent are borne by the shareholders' fund. The fund available for investment is invested by the operator and nothing will be charged to takaful fund(s). After that, both underwriting surplus and investment profit are combined, and the operator shares in the combined total base on a mudarabah pre-agreed profit share. Finally, any remaining surplus can be distributed to the participants.

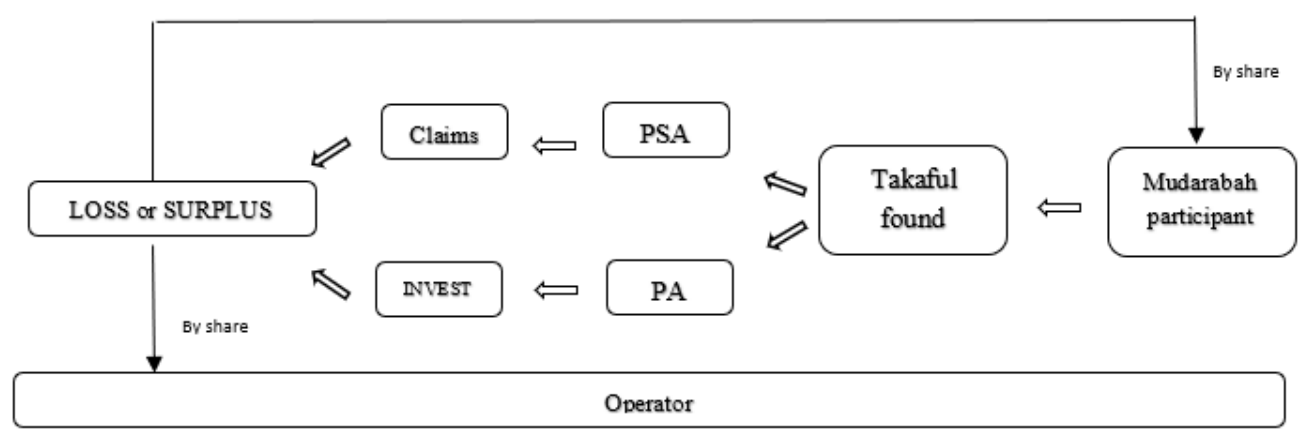

Figure 6. Takaful Mudarabah Model 


\section{c. Waqf Model}

A suggestion was made to establish the takaful fund(s) as a legal entity based on waqf. The waqf fund is a Shariah-compliant entity, capable of making its own business decisions like any corporate entity. The shareholders make initial donations for creating the waqf fund, which is subtracted from the capital of the shareholders' equity. The contributions paid by the participants are credited to the waqf fund and become the property of this fund. It should be noted that the shareholders do not have the right to the waqf fund's capital, assets, or profits; rather, their job is to make rules for and administer the fund. In case of a deficit in the waqf fund, the operator provides qard hassan to the fund to cover the deficit. However, the qard hassan will be repaid from future surpluses in the fund.

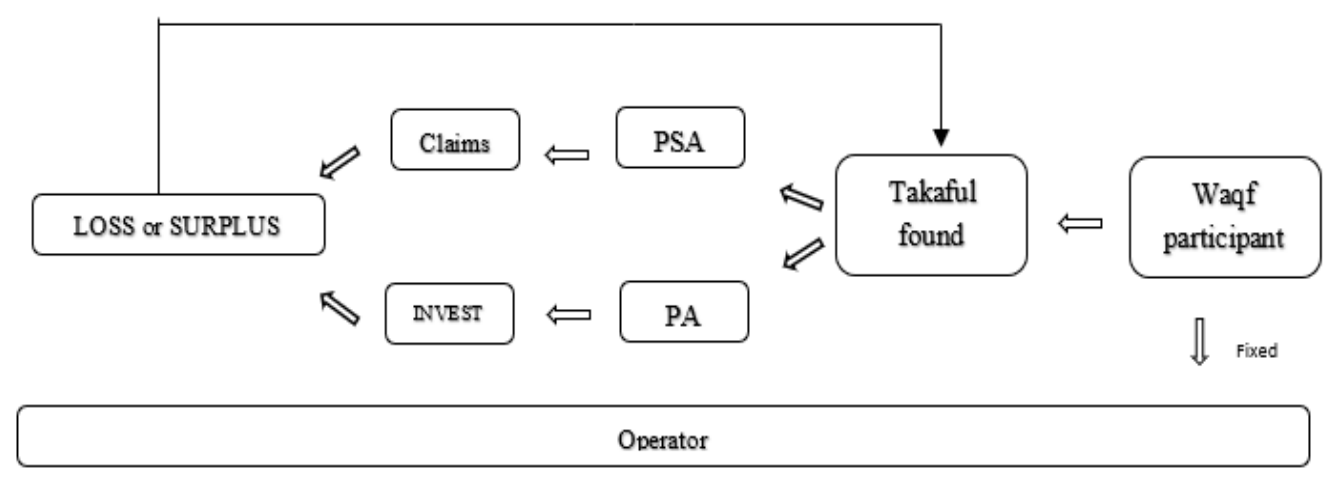

Figure 7-Takaful Waqf Model

\section{d. Hybrid Model:}

Wakalah Contract for Underwriting Activities and Mudarabah Contract for Investment Activities. This model is the most dominant in the takaful market. It is most dominant in the Middle East market and widely practiced by takaful operating companies worldwide. Moreover, this model is recommended by AAOIFI for use by takaful operators (AAOIFI, 2015). The operator used the mudarabah contract for asset management of the takaful fund(s). Under this contract, the operator acts as mudarib on behalf of participants (rab al-mal). The operator manages the assets and shares in the income generated from the investment based on a pre-agreed profit share. This ratio of profit must be agreed upon by the two parties at the inception of the contract to satisfy Shariah requirements. Unlike the wakalah, the operator receives a profit once it is generated from the investment. Otherwise, the operator will not receive any income. It should be indicated that the treatment of deficit for takaful fund(s) is 
handled in the same way as was explained in the section related to the pure wakalah model.

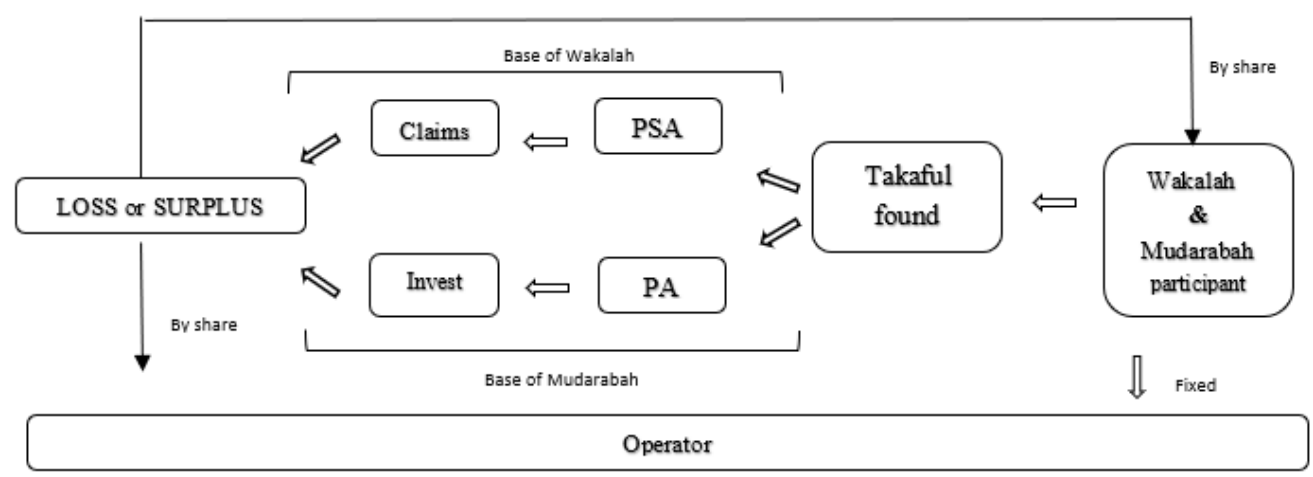

Figure 8-Takaful Hybrid Model

\section{Methodology}

A literature review typically maps the theoretical boundaries of a research field with the triple aim of taking stock of a research domain, identifying its gaps, and delineating the most promising future lines of research. To track a field's intellectual realm, objective and subjective approaches can be alternatively or jointly applied. Objective approaches to literature reviews apply bibliographic quantitative methodologies (e.g., citation analysis) and are often softwarebased; whereas subjective ones utilize qualitative methodologies, such as systematic literature reviews. On one hand, objective approaches have been increasingly adopted in review studies, including sustainability issues. To this extent, objective approaches enhance the probability to observe latent and unexpected connections between diverse literature streams. This approach is especially valued by researchers, as it allows them to overcome the cognitive biases ingrained in subjective methodologies (e.g., a researcher pointing out the features of a research field in which they are more familiar with or an expert). On the other hand, subjective approaches still successfully meet the needs of researchers to produce systematical critiques of a research field. Therefore, unsurprisingly, researchers now acknowledge the complementary capacity of objective and subjective methodologies to enable a more comprehensive understanding of the structure and specific characteristics of any research field (Pinna, 2020). 


\section{Guide to Conducting a Systematic Literature Review}

The eight major steps (see Figure 9) that one needs to take to conduct a systematic literature review. Indeed, these steps are very valuable for any kind of literature review; however, for a review to be scientifically rigorous, all of the following steps are essential

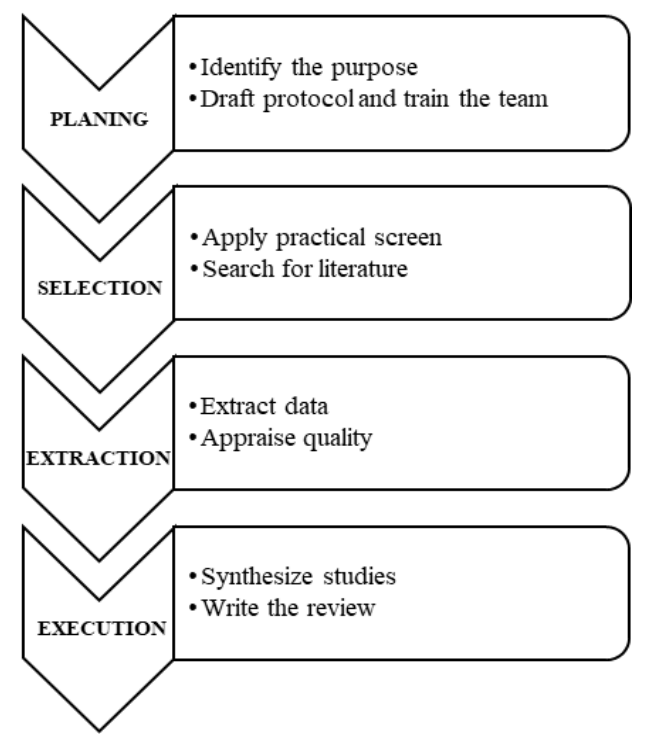

Figure 9- eight major steps of Systematic Review

1. Identify the purpose: the first step in any review requires the reviewers to clearly identify the review's purpose and intended goals, which is necessary for the review to be explicit to its readers.

2. Draft protocol and train the team: for any review that employs more than one reviewer, reviewers need to be completely clear and in agreement about the procedure they will follow, which requires both a written, detailed protocol document and training for all reviewers to ensure consistency in how they execute the review.

3. Apply practical screen: also called screening for inclusion, this step requires that the reviewers be explicit about what studies they considered for review and which ones they eliminated without further examination (a very necessary part of any literature review). For excluded studies, the reviewers must state their practical reasons for not considering them and justify how the resulting review can still be comprehensive given the practical exclusion criteria.

4. Search for literature: the reviewers need to be explicit in describing the 
details of the literature search and need to explain and justify how they assured the search's comprehensiveness.

5. Extract data: after reviewers have identified all the studies that should be included in the review, they need to systematically extract the applicable information from each study.

6. Appraise quality: also called screening for exclusion, the reviewers need to explicitly spell out the criteria they use to judge which papers they will exclude for insufficient quality. Researchers need to score all included papers, depending on the research methodologies they employ, for their quality.

7. Synthesize studies: also known as analysis, this step involves combining the facts extracted from the studies by using appropriate techniques, whether quantitative, qualitative, or both.

8. Write the review: in addition to the standard principles to be followed in writing research papers, the process of a systematic literature review needs to be reported in sufficient detail such that other researchers can independently reproduce the review's results. (Chitu, 2015).

\section{Reliability and validity in qualitative research}

Some writers have suggested that qualitative studies should be judged or evaluated according to quite different criteria from those used by quantitative researchers. Lincoln and Guba (1985) and Guba and Lincoln (1994) propose that it is necessary to specify terms and ways of establishing and assessing the quality of qualitative research that provides an alternative to reliability and validity. They propose two primary criteria for assessing a qualitative study: trustworthiness and authenticity.

\section{- Trustworthiness}

Trustworthiness is made up of four criteria, each of which has an equivalent criterion in quantitative research:

○ credibility, which parallels internal validity;

The establishment of the credibility of findings entails both ensuring that research is carried out according to the canons of good practice and submitting research findings to the members of the social world who were studied for confirmation that the investigator has correctly understood that social world. This latter technique is often referred to as respondent validation or member validation. Another technique they recommend is triangulation. 
O transferability, which parallels external validity;

Certain characteristics (that is, depth rather than the breadth that is a preoccupation in quantitative research), qualitative findings tend to be oriented to the contextual uniqueness and significance of the aspect of the social world being studied. As Lincoln and Guba put it, whether findings 'hold in some other context or even in the same context at some other time, is an empirical issue'. Instead, qualitative researchers are encouraged to produce what Geertz calls thick description that is, rich accounts of the details of a culture. Lincoln and Guba argue that a thick description provides others with what they refer to as a database for making judgements about the possible transferability of findings to another milieu.

○ dependability, which parallels reliability;

As a parallel to reliability in quantitative research, Lincoln and Guba propose the idea of dependability and argue that to establish the merit of research in terms of this criterion of trustworthiness, researchers should adopt an 'auditing' approach. This entails ensuring that complete records are kept of all phases of the research process problem formulation, selection of research participants, fieldwork notes, interview transcripts, data analysis decisions, and so on in an accessible manner. Peers would then act as auditors, possibly during the course of the research and certainly at the end to establish how far proper procedures are being and have been followed. This would include assessing the degree to which theoretical inferences can be justified.

○ confirmability, which parallels objectivity.

Confirmability is concerned with ensuring that, while recognizing that complete objectivity is impossible in social research, the researcher can be shown to have acted in good faith; in other words, it should be apparent that he or she has not overtly allowed personal values or theoretical inclinations manifestly to sway the conduct of the research and the findings deriving from it. Lincoln and Guba propose that establishing confirmability should be one of the objectives of auditors

\section{- Authenticity}

In addition to these four trustworthiness criteria, Lincoln and Guba suggest criteria of authenticity. These criteria raise a wider set of issues concerning the wider political impact of research. These are the criteria:

- Fairness. Does the research fairly represent different viewpoints among members of the social setting? 
○ Ontological authenticity. Do the research help members to arrive at a better understanding of their social milieu?

- Educative authenticity. Do the research help members to appreciate better the perspectives of other members of their social setting?

- Catalytic authenticity. Has the research acted as an impetus to members to engage in action to change their circumstances?

○ Tactical authenticity. Has the research empowered members to take the steps necessary for engaging in action?

The authenticity criteria are thought-provoking but have not been influential, and their emphasis on the wider impact of research is controversial. They have certain points of affinity with action research, which by and large has not been a popular form of social research, though it has had some impact in fields like organization studies and education. The emphasis on practical outcomes differentiates it from most social research.

Considering the main purpose of the research which is to Offering Catastrophic Risk Management Framework by Alternative Risk Transfer Instruments to Islamic Capital Market with cat takaful (CT) sukuk. In the present research, in the first stage, by using the Designated search keywords as described in Table 3, Farsi and English Academic sources were searched.

Table 3- Designated search keywords

\begin{tabular}{|c|c|c|}
\hline Keywords & Resources & Result \\
\hline \multirow{2}{*}{$\begin{array}{ll}\text { - } & \text { Insurance-linked securities } \\
\text { - } & \text { Alternative risk transferred } \\
\text { instruments } \\
\text { - } & \text { Cat bond \& catastrophe } \\
\text { bonds } & \\
\text { - } & \text { Iran catastrophe risks } \\
\text { - } & \text { Insurance Sukuk }\end{array}$} & Farsi & $\begin{array}{l}\text { The total number of findings based on } \\
\text { keywords was } T \text { rarticles. Trarticles } \\
\text { were used for systematic review. And } \\
\text { others based on the research protocol } \\
\text { due to lack of relevance to the topic, } \\
\text { Not scientific research, Duplication in } \\
\text { different sources. Were Refined and } \\
\text { removed. }\end{array}$ \\
\hline & English & $\begin{array}{l}\text { Numerous sources were found. From } \\
\text { the article and the book, the Refined } \\
\text { and selected number was } 0 \text {. sources, } \\
\text { which were removed several times } \\
\text { more than this number according to } \\
\text { the research protocols. }\end{array}$ \\
\hline
\end{tabular}

Based on the 8 steps of the systematic review research method \& according to the research protocol (Figure 10) after the refining process, 23 
Farsi articles and 50 English articles were selected. The Sukuk model presented in the research was implemented Based on the extracted concepts from written sources, Designed and presented.

1. Due to the multiplicity of alternative risk transfer instruments, the focus will be on the main types, the catastrophic bonds and tried to focus mainly on this content so other issues were left out

2. Duplicate findings that did not contain new material

3. Content that is pure insurance or mathematical bases and not related to the structure of interdisciplinary tools

4. Inability to access the full texts of articles, books, reports and reference databases

Figure 10- Research protocol

In the second stage, selecting 18 Expert interviewees by Judgmental Sampling (purposive sampling) \& Snowball sampling Action was taken according to the predetermined protocol. (Figure 11)

1. Financial specialist with a PhD degree in finance, insurance or economics and also a related executive and managerial background

2. Specialist in Islamic financial jurisprudence with the condition of membership in the jurisprudential committee of the Stock Exchange or Central Bank or Central Insurance

3. International Insurance Specialist, provided they have international specialized qualifications (like Chartered Insurance Institute (CII)) And also executive operational experience

4. International financial specialist with experience in issuing and designing financial instruments in global markets

Figure 11- Interviewer Selection Protocol

Due to the limited number of Pundits and experts on the subject of research, The Delphi method was used to obtain the opinion of experts and their opinion was modified and implemented in the proposed model. In the open coding stage, 415 concepts were extracted which were classified into 10 categories and finally presented in 4 Propositions/themes as described in Table 4.

Table 4-coding classification

\begin{tabular}{|c|c|c|}
\hline Concepts & Categories & Propositions/themes \\
\hline $\begin{array}{ll}- & \text { Circumvent sanctions } \\
- & \text { Sanctions as an opportunity } \\
- & \text { Restrictions resulting from } \\
\text { sanctions } & \end{array}$ & Focused on sanctions & \multirow[t]{2}{*}{ - $\quad$ Necessity } \\
\hline $\begin{array}{ll}- & \text { National's needs } \\
\text { - } & \text { Insurance company's needs } \\
\text { - } & \text { Capital market's needs } \\
\end{array}$ & $\begin{array}{l}\text { Focuses on the needs } \\
\text { of customers and stakeholders }\end{array}$ & \\
\hline $\begin{array}{ll}- & \text { National culture building } \\
- & \text { Culturalization of performers } \\
\text { - } & \text { Culturalization of investors }\end{array}$ & $\begin{array}{l}\text { - Culturalization } \\
\text { requirements }\end{array}$ & $\begin{array}{l}\text { - Implementation } \\
\text { foundation }\end{array}$ \\
\hline
\end{tabular}


Offering Catastrophic Risk Management Framework by...

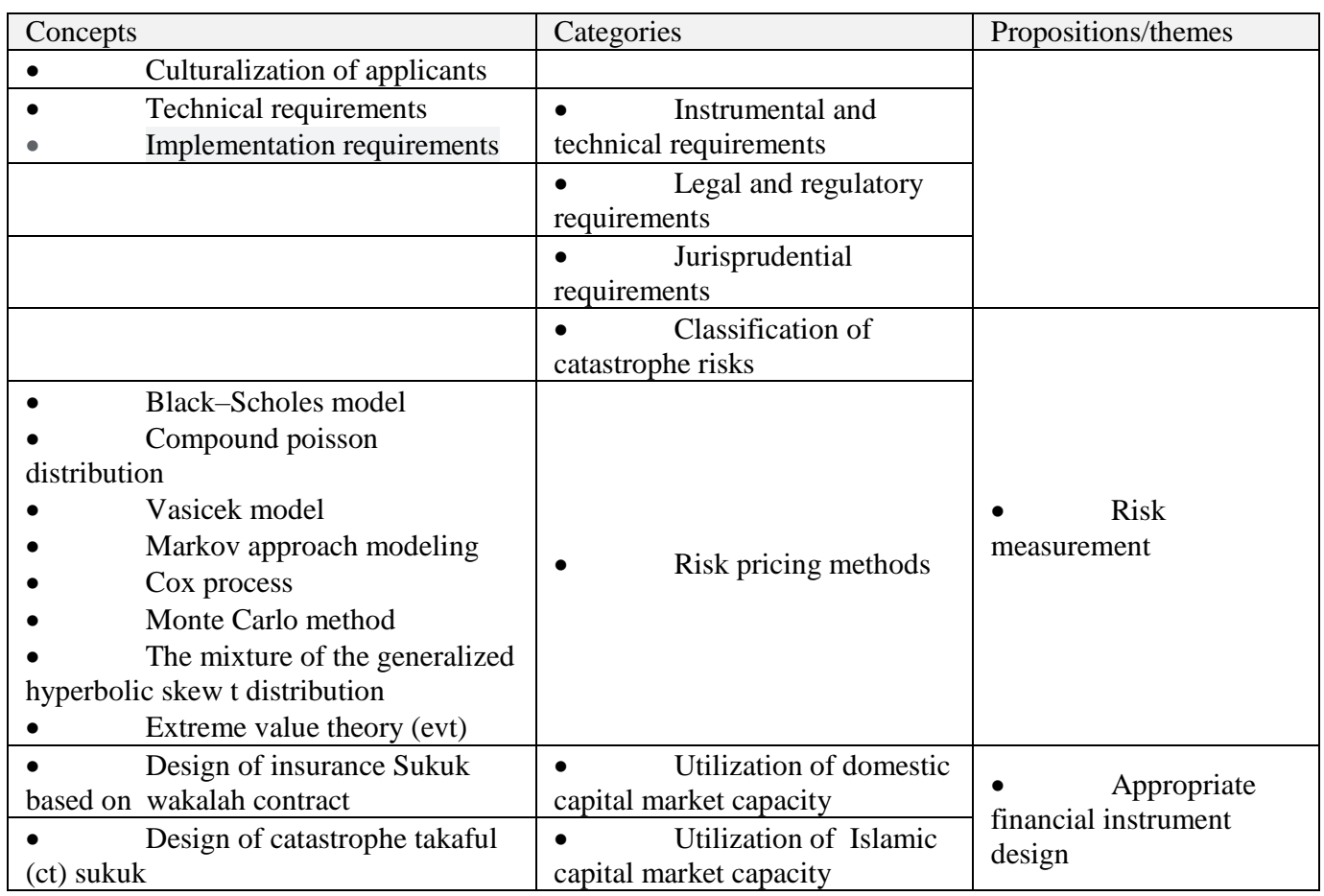

Based on the explanations provided about the four-stage model of Lincoln and Guba and also its complementary step, the trustworthiness and authenticity steps of the present research are presented in Table 5.

Table 5- trustworthiness and authenticity

\begin{tabular}{|l|l|l|l|}
\hline \multicolumn{3}{|c|}{ Trustworthiness } \\
\hline internal & credibility & technique & Performed in research \\
\hline validity & & $\begin{array}{l}\text { To ensure that the information is accurate, the first } \\
\text { stage is the accuracy and sensitivity of selecting experts } \\
\text { for interviews based on research selection protocol, } \\
\text { after that conducting the interview The transcript of the } \\
\text { interview was transcribed. The results of the analysis } \\
\text { performed offer to the interviewee. According to the } \\
\text { opinions and findings, a continuous review has been } \\
\text { done (self-monitoring). This act Repeated twice during } \\
\text { the research process and the end of the work by two } \\
\text { External observers (peer debriefing). ( respondent } \\
\text { validation) }\end{array}$ \\
\hline
\end{tabular}




\section{Iranian Journal of Finance, 2021, Vol. 5, No. 3 (Hasangholipoure,H.)}

\begin{tabular}{|c|c|c|c|}
\hline $\begin{array}{l}\text { external } \\
\text { validity }\end{array}$ & transferability & 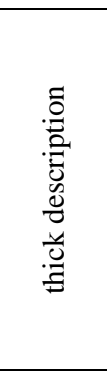 & $\begin{array}{l}\text { During the research and also the data collection stage, } \\
\text { an attempt was made to scrutinize the different aspects } \\
\text { and dimensions of the study position from different } \\
\text { angles. predetermined procedures in coding and } \\
\text { analysis were used. Our effort has been that, By } \\
\text { providing more details about the participants, Accurate } \\
\text { and purposeful description of the activities performed } \\
\& \text { Mapping the direction of this research, to Make it } \\
\text { possible for others to understand the characteristics and } \\
\text { aspects of the research subject. }\end{array}$ \\
\hline reliability & dependability & 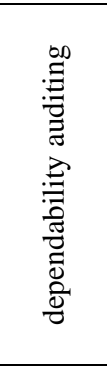 & $\begin{array}{l}\text { During the research process, an attempt was made to } \\
\text { provide sufficient evidence related to the research } \\
\text { subject in a detailed and comprehensive. After that } \\
\text { complete records are kept of all phases of the research } \\
\text { process, selection of research participants, fieldwork } \\
\text { notes, interview transcripts, their analysis, and so on in } \\
\text { an accessible manner. to establish how far proper } \\
\text { procedures are being and have been followed Peers } \\
\text { acted as auditors during the course of the research and } \\
\text { at the end, so confirms the research process. }\end{array}$ \\
\hline objectivity & confirmability & 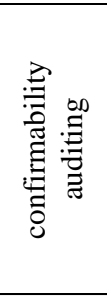 & $\begin{array}{l}\text { complete records are kept of all phases of the research } \\
\text { process, selection of research participants, fieldwork } \\
\text { notes, interview transcripts, the analysis, and so on. } \\
\text { Finally, to ensure that the results are the answers of the } \\
\text { participants and also Far from the Researcher biases } \\
\text { and prejudices. the research process and obtaining the } \\
\text { results were reviewed and approved by the research } \\
\text { team (supervisor and dissertation consultants). }\end{array}$ \\
\hline \multicolumn{4}{|c|}{ Authenticity } \\
\hline \multicolumn{4}{|c|}{$\begin{array}{l}\text { Considering the efforts to be comprehensive in the research process and to be careful in selecting the } \\
\text { interviewees and to avoid biasing the researchers' perceptions, this research fairly represents different } \\
\text { viewpoints among members of the social setting (Fairness) } \\
\text { Given that an attempt has been made to follow the research process with an expert and pragmatic view, } \\
\text { the researchers' perception is that the present research help members to arrive at a better understanding of } \\
\text { their social milieu. (Ontological authenticity) } \\
\text { Due to the careful selection of interviewees and the use of the snowball method in the research process, } \\
\text { the researchers' perception is that the present research helps members to appreciate better the perspectives } \\
\text { of other members of their social setting. (Educative authenticity) } \\
\text { Given that the present study is a response to the existing and tangible needs of the country's financial and } \\
\text { insurance industry, the researchers' perception is that the present research acted as an impetus to members } \\
\text { to engage in action to change their circumstances. (Catalytic authenticity) } \\
\text { Given that the present study tried to Offering Catastrophic Risk Management Framework by Alternative } \\
\text { Risk Transfer Instruments to Islamic Capital Market with cat takaful (CT) sukuk, the researchers' } \\
\text { perception is that the present study has empowered members to take the steps necessary for engaging in } \\
\text { action. (Tactical authenticity) }\end{array}$} \\
\hline
\end{tabular}




\section{Research findings}

Macro-design of catastrophic bond is to increase the insurance capacity and split risk exposure to different markets. The best conceptual equivalent of these in Islamic financial instruments is Takaful, as defined means a joint guarantee. Thus, it can be visualized as a pact among a group of members or participants who agree to jointly guarantee among themselves against loss or damage that may be inflicted upon any of them as defined in the pact. Should any member or participant suffer a catastrophe or disaster, he receives a certain sum of money or financial benefit from a fund, as also defined in the pact, to help him meet the loss or damage. In other words, the basic objective of Takaful is to pay for a defined loss from a defined fund. Each member of the group pools efforts to support the needy. It means mutual help among the group. (Ma'Sum Billah, 2019, p325) so Takaful is the best way to insure the material or one's life security against risks of catastrophes or disaster. The elements of cooperation, solidarity and brotherhood in Takaful should be inculcated into Muslims specifically and into the public in general. Finally, as a result Combining catastrophic bond and takaful can have the benefits of both financial instruments, so Based on the results of the current research, Cat Takaful (CT) presented as follows:

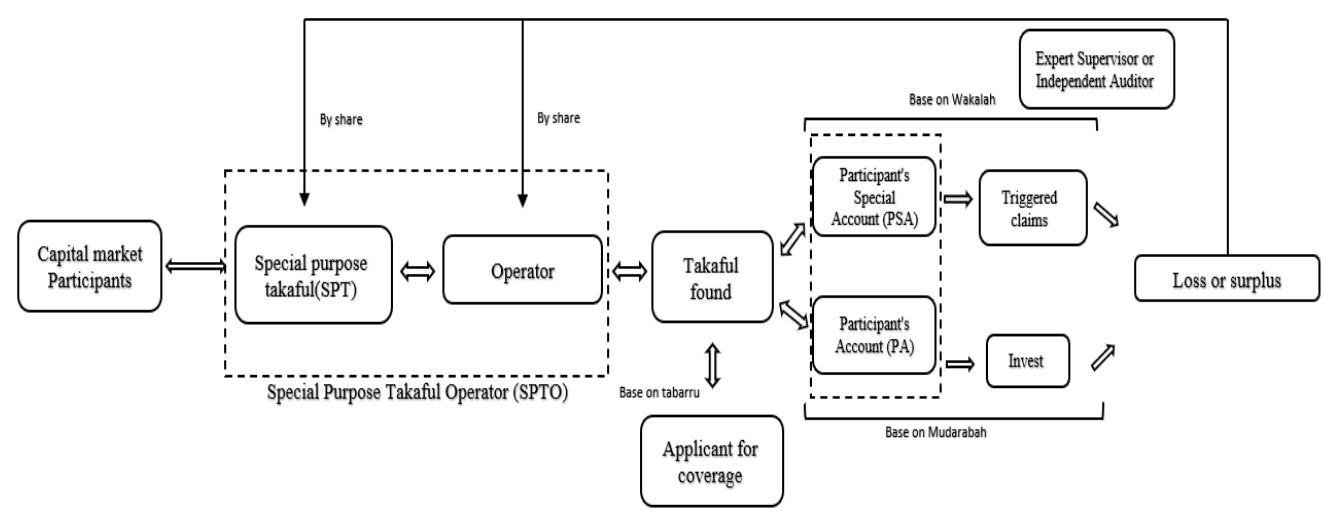

Figure 12- Cat Takaful (CT) Sukuk structure

\section{a. Applicant to Provide Coverage}

The applicant to provide coverage for his catastrophe exposure, after receiving the necessary permits, will issue Cat Takaful Sukuk in the capital market in return, they pay a sum(base on actuary) to the Takaful Fund As a donation(based on tabarru) or as an interest-free loan(based on Qard al-Hasan), This amount paid to the Takaful Fund will be added to the amounts received 
from the capital market participants, the benefits from the investment of these funds at the end of the contract period will belong to the capital market participants, if the amount received as an interest-free loan, principal Will be returned to the applicant, and if in the case of donation received, all amount will belong to the capital market participants.

b. capital market participants

Capital market participants enter the takaful business through this financial instrument and will benefit from its direct benefits. On the other hand, due to the uncorrelated return from this type of securities in comparison with other investment portfolios of these capital market participants, they will reduce the total risk of their investment portfolio too. Returns will be obtained from two sources, one for the investment of the principal funds paid by the participants and the other return (principal and return) from the investment of the applicant's payments to the Takaful Fund.

In conventional insurance, insurers went to insurance companies to obtained cover for their risks and based on this an insurance contract was created. In this Sukuk, applicants for coverage can refer to the capital market as the buyer of this product and, according to the existing Takaful contract, provide coverage for themselves and benefit from the takaful fund investment income too.

\section{c. Special purpose takaful (SPT) \& Special Purpose Takaful Operator (SPTO)}

The main task of the SPT is the packaging and transferring insurance risks, SPT is a kind of SPV is set up under the capital market law (financial industry task). And for its takaful activity need to authorization from the takaful supervision. Therefore, SPT is a Limited Liability Takaful Company with a special purpose to provide cover for sponsor's perils, back to cash deposit arising from the Sukuk issuance. The SPT is dissolved after the expiration of the contract.

Special Purpose Takaful Operator (SPTO) is a new generation of SPT that is practically established by operating companies and perform both activities together. It has all the capabilities of SPT and acts as an operator too. In this structure

The relationship between a Special purpose takaful (SPT) and investors was designed as a relationship between a lawyer and a client (Wakalah), that the SPT has a proxy in two subjects:

Clients (investors OR Participants) pay their funds by purchasing Sukuk, the SPT must be invested in a risk-free Shariah Compliant Financial instrument 
(To maintain the principle of capital). Income accrued to investors included Investment income in risk-free or low-risk securities (Base of Final Profits from Participant's Account (PA)) plus Share received from Takaful contract (Base of Final Profits from Participant's Special Account (PSA)), in accordance with the provisions of the attorney contract.

back to the amount of money collected from the Sukuk Cat Takaful (CT), SPT acts as a Takaful Company(insurer) in this structure (regard to the Takaful capability) and Provide coverage up to the ceiling of Sukuk nominal value provides for sponsor (issuer of this Sukuk who need the coverage).

\section{d. Operator}

Takaful Operator or Trustee means a professional expert and authorized company who is working in its capacity and the terms as Wakeel thereby operating the TF. (Operator or Trustee may be used interchangeably). The Takaful Operator creates the TF by ceding the amount collected from the capital market participants. TF is the only source of revenue for the Takaful Operator. The Operator deducts 'Wakalah Fee' for operating the TF and The Operator may either charge a fixed Wakalatul Istismar Fee from or earn a profit share in a Modaraba agreement with the TF as part of investment management services rendered. From the TF, the Operator deducts the Wakalah Fee for Operating the TF and Wakalatul-Istismar Fee/Modaraba Profit for managing investments in the TF on behalf of the TF. Surplus is unique to Takaful business, in case the net Contribution for the Participant is negative, no surplus would be paid to that Participant and in case there is a deficit in the TF, the Takaful Operator will donate an interest-free loan to be called Qard-e-Hasana to make good the shortfall in the fund. The loan shall be repaid from the future surpluses generated in the TF

e. Takaful Fund (TF)

$\mathrm{TF}$ is a separate and independent entity capable of having title to ownership of, and possession of assets whether in the form of sums of money, movable and immovable properties, and/or in any other tangible or intangible form legally possible and permissible along with the compliance with the Shariah principles. The objects and purposes of the TF are as follows:

- To receive contributions, donations, gifts, charities, subscriptions etc., from the participants and others.

- To provide relief to the participants against benefits defined as per the TF rules and any takaful supplementary benefit document(s). 
- To give charities in consultation with the shariah board.

- To invest monies of the TF in and subscribe for, take, acquire, trade or deal in, instruments approved by the shariah board such as shares, stocks, Sukuk, bonds, securities or investments of redeemable capital of any other company, institution, mutual fund, corporation or body corporate or any other manner;

- To do all such other things/acts/objects as are incidental or conducive to the attainment of the above objects or any of them (Malik Adnan,2019-p 7172)

\section{f. Participant's Account (PA)}

A certain percentage of the funds are kept in this account, according to the terms of the contract and the takaful fund strategy to invest in risk-free or lowrisk securities \& high return and immediate liquidity financial instruments. The attorney will have deposited the money in the bank low-risk account and also invest in the fixed income securities, based on the engineered structure and that way paying the interest to their clients at the maturity date (if any) will be paid.

\section{g. Participant's Special Account (PSA)}

A certain percentage of the funds are kept in this account, according to the terms of the contract and the takaful fund strategy and actuary of Cat Takaful (CT) Sukuk, so the Money collects from the Sukuk issued (nominal value) are considered as collateral for takaful and should always be guaranteed by the coverage of the cash fund. Any investment arrangements for obtaining higher returns should be with the consent of the parties to the contract and subject to the maintenance of the principal amount of the collateral. Note: These two accounts can also operate as a single unit with different strategies based on the Takaful contract design.

\section{h. Expert Supervisor or Independent Auditor}

An independent and specialized institution to detect and announce the occurrence of the accident and activate the trigger mechanism for these Sukuk. Applicant notifies the operator in writing about the loss or damage indicating as to its nature and extent and lodges a claim, after obtaining approval from this independent expert is paid from the TF. 


\section{Conclusion}

During human life in different societies, natural and catastrophic events lead to life-threatening destructions, and financial losses continue to be incurred. In other words, the risk of an accident or disaster is more a direct result of human activities. Societies use scientific and technological capabilities by using financial innovative methods and capital market potentials to be able to cope with these disasters and transfer the catastrophic risks to reduce the amount of damage caused by such perils. Out of the total cities of Iran, only $33 \%$ are in low-risk areas and out of 64 possible catastrophic events in the whole world, about 34 of them have been experienced, about $75 \%$ of the country's population centers are at floods risk and more than $80 \%$ of the countries are exposed to other natural disasters risks such as earthquakes exposure. Domestic insurance capacity does not cover this volume of risk and the need for external reinsurance capacity is always felt. Catastrophe bonds structure allows an issuing institution to transfer catastrophic exposures and risks to investors by creating capital relief and additional risk capacity. Macro-design of catastrophic bond is to increase the insurance capacity and split risk exposure to different markets. The best conceptual equivalent of these in international Islamic financial instruments is Takaful, as defined means a joint guarantee. The basic objective of Takaful is to pay for a defined loss from a defined fund. Each member of the group pools efforts to support the needy. It means mutual help among the group, so Takaful is the best way to insure the material or one's life security against risks of catastrophes or disaster. The elements of cooperation, solidarity and brotherhood in Takaful should be inculcated into Muslims specifically and into the public in general. We adjusted the formal cat bonds structure with the Islamic jurisprudence. According to the systematic review research method 8 steps, the Sukuk model was implemented based on the extracted concepts from 23 Farsi articles and 50 English articles. After that interviews by 18 experts who were selected by purposive \& Snowball sampling, The Delphi method was used to obtain the opinion of experts and their opinion was modified and implemented in the final model. In the open coding stage, 415 concepts were extracted which were classified into 10 categories and finally presented in 4 Propositions/themes. the trustworthiness and authenticity did base on the four-stage model of Lincoln and Guba and also its complementary step. Finally, as result Combining catastrophic bond and takaful can have benefits for both financial instruments, based on the results of the current research, Cat Takaful (CT) structure to utilization the Islamic capital market capacity and an answer to the growing need to create Insurance capacity to cover catastrophic exposure presented. 
Funding: This research received no external funding.

\section{References}

AAOIFI. (2015). Shariah Standard no (26). P 879. Islamic Insurance accounting and auditing organization for Islamic financial institutions

Adrc.(2021). Asian disaster reduction centre. www.glidenumber.net.

Ariff, Mohamed. (2014). Sukuk securities new ways of debt contracting. John Wiley \& sons Singapore pte. Ltd.

Banks, Erik, (2004). alternative risk transfer: integrated risk management through insurance, reinsurance and the capital markets. John Wiley \& sons ltd,

Banks, Erik. (2005). catastrophic risk analysis and management. John Wiley \& sons ltd,

Billah, m. M. (2005). sharia model of quantum of damages in takaful \&retakaful. International Islamic University Malaysia (Iium).

Chitu, Okol. (2015). A Guide to Conducting a Standalone Systematic Literature Review. (Volume 37 Article 43). Communications of the Association for Information Systems.

Em-dat. (2021). emergency events database, www.emdat.be.

Iranian studies group at MIT, (2004). earthquake management in Iran a compilation of literature on earthquake management. www.web.mit.edu/isg/publications.htm

Krutov, Alex. (2010). investing in insurance risk insurance: insurancelinked securities a practitioner's perspective. published by risk books, a division of incisive financial publishing ltd.

Malik, Adnan. (2019). introduction to takaful theory and practice. Springer.

Ma'sum billah, mohd. (2019). Islamic insurance products exploring takaful principles, instruments and structures. Springer.

Mousavian, Seyyed Abbas et al. (2015). Islamic insurance instrument to transfer the risk in the oil industry. (no 8) "Islamic finance researches.

Mousavian, Seyyed abbas. (2007). announced negotiations of Iran shariah board of securities and exchange organization and their descriptions. www.rdis.ir. 
Mousavian, Seyyed abbas. (2009). Islamic financial tools. publication organization of Islamic research institute for culture and thought.

Ndmo. (2017). national disaster management organization of Iran, Iran and catastrophe event. www. ndmo.ir.

Niehaus, Greg. (2002). the allocation of catastrophe risk. (no 26). Journal of banking \& finance.

Pinna, Mariella. (2020). Sustainable Entrepreneurship a Systematic Review of Academic Research. Springer Nature Switzerland.

RDIS. (2017) . Iran shariah board of securities and exchange organization, classification of Islamic financial instruments (Sukuk). www.rdis.ir.

SECP. (2019). Takaful guide. securities and exchange commission of Pakistan. www.jamapunji.pk.

Undrr, (2021), United Nations desinventar open source initiative, www.desinventar.net.

Bibliographic information of this paper for citing:

Hasangholipoure, Hosaine; Chirani, Ebrahim; Mirbargkar, Seyed mozaffar \& Kheradyar, Sina; (2021). Offering Catastrophic Risk Management Framework by Alternative Risk Transfer Instruments to Islamic Capital Market with Cat Takaful (CT) Sukuk. Iranian Journal of Finance, 5(3), 78-107.

Copyright $\odot$ 2021, Hosaine Hasangholipoure, Ebrahim Chirani, Seyed mozaffar Mirbargkar and Sina Kheradyar 